\title{
Morphine Enhances Doxorubicin-Induced Cardiotoxicity in the Rat
}

\author{
Lisa Drange Hole • Terje Hjalmar Larsen • \\ Kjell Ove Fossan · Fredrik Limé · Jan Schjøtt
}

Published online: 15 February 2014

(C) The Author(s) 2014. This article is published with open access at Springerlink.com

\begin{abstract}
Interventions to reduce the cardiotoxicity of doxorubicin are clinically relevant. Pharmacological preconditioning mimicking ischemic preconditioning has been demonstrated with morphine and represents an acceptable clinical intervention. The purpose of this study was to examine if pretreatment in vivo with morphine could reduce doxorubicin-induced cardiotoxicity ex vivo in a rat model. Wistar rats were divided into six groups and pretreated with an intraperitoneal (i.p.) injection of 3 or $10 \mathrm{mg} / \mathrm{kg}$ morphine, $1 \mathrm{mg} / \mathrm{kg}$ naloxone and saline, $1 \mathrm{mg} /$ $\mathrm{kg}$ naloxone and $3 \mathrm{mg} / \mathrm{kg}$ morphine or saline, $60 \mathrm{~min}$ before excision of the heart. Biochemical indices such as troponin $\mathrm{T}(\mathrm{TnT})$ and hydrogen peroxide $\left(\mathrm{H}_{2} \mathrm{O}_{2}\right)$ in effluate were measured together with physiological parameters in Langendorff hearts before and after doxorubicin infusion $(2 \mathrm{mg} / \mathrm{mL} 0.05 \mathrm{~mL} / \mathrm{min}$ for $45 \mathrm{~min}$ ). Myocardial content of doxorubicin was measured at the end of infusion. Pretreatment with morphine, irrespective of dosage, produced a significant loss in left ventricular-developed pressure and
\end{abstract}

L. D. Hole · J. Schjøtt

Faculty of Medicine and Dentistry, Institute of Clinical Science, University of Bergen, 5021 Bergen, Norway

L. D. Hole $(\bowtie) \cdot$ K. O. Fossan · F. Limé · J. Schjøtt Laboratory of Clinical Biochemistry, Section of Clinical Pharmacology, Haukeland University Hospital, 5021 Bergen, Norway

e-mail: lisa.drange.hole@helse-bergen.no

\section{T. H. Larsen}

Institute of Biomedicine, University of Bergen, 5021 Bergen, Norway

\section{T. H. Larsen}

Department of Heart Disease, Haukeland University Hospital, 5021 Bergen, Norway an increase of TnT and $\mathrm{H}_{2} \mathrm{O}_{2}$ in effluate before doxorubicin infusion $(p<0.05)$. Morphine also produced a significant increase in left ventricular end-diastolic pressure and an increase of TnT and $\mathrm{H}_{2} \mathrm{O}_{2}$ in effluate $(p<0.05)$ at the end of doxorubicin infusion. Naloxone, a non-selective opioid receptor antagonist, abolished the effects of morphine both before and after doxorubicin infusion. Morphine, irrespective of dosage, increased myocardial content of doxorubicin compared to pretreatment with saline $(p<0.05)$. Pretreatment with morphine is associated with a cardiodepressive effect and enhances cardiotoxicity of doxorubicin measured by increased myocardial accumulation of doxorubicin and physiological and biochemical indices. The negative effects observed in our rat model are abolished by naloxone.

Keywords Doxorubicin - High-sensitivity cardiac troponin $\mathrm{T} \cdot$ Hydrogen peroxide $\cdot$ Heart - Doxorubicinol . Cardiotoxicity

\section{Introduction}

The anthracycline doxorubicin is a frequently prescribed anticancer drug because of its effect on solid tumors as well as haematological malignancies. However, its pronounced cardiotoxicity limits long-term use and prevents effective anticancer therapy [1]. Dose reduction protocols to avoid the risk of delayed cardiotoxicity might be at the expense of the anticancer effect [2]. Generation of reactive oxygen species (ROS) and impaired calcium handling have been proposed as toxic mechanisms to explain both acute and delayed cardiotoxicity of anthracyclines [3-5].

Measurement of cardio-specific biomarkers can be a valid diagnostic tool for early identification, assessment 
and monitoring of cardiotoxicity [6]. Cardiac troponins have been suggested as valuable biomarkers of anthracycline cardiotoxicity, both in animal and clinical studies [7, 8], and they are advantageous because samples are obtained by a minimally invasive procedure and easily analyzed. However, few reported studies have characterized the cardiac troponin response in chemically induced chronic progressive myocardial injury such as we see with doxorubicin exposure [9]. The sensitivity and precision of the troponin $\mathrm{T}(\mathrm{TnT})$ assays have been improved in recent years and clinically approved high-sensitivity assays now detect cardiac troponins in nanogram per liter concentration.

Morphine is a non-selective opioid receptor agonist. Direct stimulation of myocardial $\delta_{1}$-opioid receptors leads to activation of mitochondrial $\mathrm{K}_{\mathrm{ATP}}$-channels and a resultant increase in intracellular ROS in vitro. This is an important component of the signaling pathways by which morphine mimics preconditioning in cardiomyocytes [10]. Pharmacological preconditioning with morphine could represent an acceptable clinical intervention to reduce the cardiotoxicity of doxorubicin. Thus, it is of interest to study how morphine interacts with the toxic mechanisms of anthracyclines by measuring generation of ROS. To our knowledge, only one study has previously investigated the cardiac effect of intraperitoneal (i.p.) morphine before doxorubicin i.p. in rats, and this study found that morphine protects against doxorubicin cardiotoxicity [11]. A previous pilot study of 2-week duration, where we pretreated rats in vivo with i.p. morphine or saline $60 \mathrm{~min}$ before i.p. doxorubicin, every other day for 11 days, found that morphine, on the contrary, increased mortality in combination with doxorubicin [28].

In order to explore our negative findings in the pilot study, we pretreated rats in vivo with morphine before the hearts were isolated and exposed to doxorubicin ex vivo in a Langendorff model. Naloxone, a non-selective opioid receptor antagonist, was administered to investigate whether the potential effect of morphine would be abolished, or if naloxone itself had an effect. The aim of this study was to investigate the interaction of morphine and doxorubicin exclusively in the heart. Measurement of relevant biochemical indices such as TnT and hydrogen peroxide $\left(\mathrm{H}_{2} \mathrm{O}_{2}\right)$ in effluate combined with physiological parameters and myocardial content of doxorubicin were included in the model.

\section{Materials and Methods}

Materials

Doxorubicin was purchased from Meda AS (Slemmestad, Norway), morphine, naloxone and pentobarbital from
Haukeland Hospital Pharmacy (Bergen, Norway), heparin from Leo Pharma A/S (Oslo, Norway), and ingredients for the Krebs-Henseleit bicarbonate buffer from Merck KGaA (Darmstadt, Germany). This study conforms to the guide for the care and use of laboratory animals published by the US National Institutes of Health (NIH publication no. 85-23, revised 1996) and was approved by the Animal Care and User Committee in Norway.

Animals

Male Wistar rats weighing $200 \pm 20 \mathrm{~g}$ were purchased from Taconic (Ejby, Denmark). The animals were housed in grid-bottom metal wire cages in a room maintained at a $12 \mathrm{~h}$ light-dark cycle at a temperature of $20-22{ }^{\circ} \mathrm{C}$. They were acclimatized for 2 weeks, housed four per cage and allowed free access to food pellets (Pellets rodent, Special Diets Services, Essex, UK) and tap water until injection of morphine, naloxone, saline or doxorubicin. The animals were separated in individual cages based on their respective treatment protocols.

\section{Langendorff Perfusion Model}

The perfusion medium was a modified, oxygenated $(95 \%$ $\left.\begin{array}{llll}\mathrm{O}_{2} & \text { and } 5 & \% & \mathrm{CO}_{2}\end{array}\right)$ Krebs-Henseleit bicarbonate buffer (KHBB) (pH 7.4) containing in $\mathrm{mM}$ : $118.5 \mathrm{NaCl}, 25.0$ $\mathrm{NaHCO}_{3}, 1.2 \mathrm{MgSO}_{4}, 4.7 \mathrm{KCl}, 1.2 \mathrm{KH}_{2} \mathrm{PO}_{4}, 11.0$ D-glucose, and $1.25 \mathrm{CaCl}_{2}$. Hearts were excised after anesthesia of the rats with an i.p. injection of pentobarbital $50 \mathrm{mg} / \mathrm{kg}$ $(0.1 \mathrm{~mL} / 100 \mathrm{~g}$ bodyweight $)$ and heparinized i.p. $(0.1 \mathrm{~mL}$ $500 \mathrm{IU} / 100 \mathrm{~g}$ bodyweight). Anesthesia was evaluated by the pedal-withdrawal reflex. The heart was rapidly excised and immediately placed in cold $\left(4{ }^{\circ} \mathrm{C}\right) \mathrm{KHBB}$ to temporarily stop its beating and preserve it from ischemic injury prior to perfusion. The heart was mounted on a steel cannula placed in the aorta and perfused retrogradely in a Langendorff system with the use of thermostated $\left(37^{\circ} \mathrm{C}\right)$ reservoirs (Lauda, Lauda-Königshofen, Germany), perfusion lines and heart chamber. Volume-regulated flow $(12.5 \mathrm{~mL} / \mathrm{min})$ was performed by use of an Alitea peristaltic pump (Alitea, Stockholm, Sweden). A perfusion pump (B. Braun, Melsungen, Germany) connected to a side arm of the aortic cannula was used for administration of doxorubicin or KHBB ex vivo. A water-filled latex balloon was placed in the left ventricle and connected to a pressure transducer (Memscap AS, Skoppum, Norway) for the recording of left ventricular pressure (LVDP) and secondarily derived contractility indices. Left ventricular enddiastolic pressure (LVEDP) was adjusted between 4 and $8 \mathrm{mmHg}$. A second pressure transducer was connected to a side arm on the aortic cannula for the recording of aortic pressure (AoP), as an index of coronary vascular resistance 
during volume-regulated perfusion. Pressure signals were amplified (Quadbridge, AD Instruments, London, UK) and recorded using a PowerLab data acquisition system (AD Instruments, East Sussex, UK). AoP, LVDP, LVEDP, left ventricular pressure first derivatives maximum $\left(\mathrm{d} p / \mathrm{d} t_{\max }\right)$ and minimum $\left(\mathrm{d} p / \mathrm{d} t_{\min }\right)$ were displayed and recorded. Pacing ( 300 beats per minute by electric stimulation of $5 \mathrm{~V}$ amplitude of $3 \mathrm{~ms}$ duration) during the doxorubicin or KHBB ex vivo protocol was obtained by placing one electrode on the right auricle and one on the steel cannula. Pacing was used to maintain a standard contractile response to the experimental drugs in the model not influenced by changes in heart rate and/or periods of arrhythmia. Effluate of KHBB mixed with doxorubicin was sampled for measurements of doxorubicin concentration in the perfusion system before mounting of the hearts. Effluate samples of $1 \mathrm{~mL}$ were collected in $1.5 \mathrm{~mL}$ polypropylene Eppendorf micro-test tubes (Eppendorf Vertrieb, Wesseling-Berzdorf, Germany) from each heart, at baseline and at the end of the perfusion protocol, and stored at $0^{\circ} \mathrm{C}$, until analysis for TnT within 4 days of termination of the Langendorff protocol. Effluate samples of $1 \mathrm{~mL}$ were collected in Eppendorf tubes from each heart, at baseline and at the end of the perfusion protocol, and immediately analyzed for $\mathrm{H}_{2} \mathrm{O}_{2}$. Samples were placed in a thermostated $\left(37^{\circ} \mathrm{C}\right)$ Eppendorf rack heated by a Lauda reservoir (Lauda, Königshofen, Germany). At the end of the perfusion protocol, hearts were removed from the Langendorff system, and myocardial tissue from the left ventricle was dissected free and immediately frozen in liquid helium and stored at $-80{ }^{\circ} \mathrm{C}$ until analysis of doxorubicin and doxorubicinol within 14 days of termination of the Langendorff protocol. All experiments and analysis were carried out between 7 a.m. and 7 p.m.

\section{Experimental Design}

Rats were randomly divided into three morphine treatment groups ( 3 or $10 \mathrm{mg} / \mathrm{kg}$ morphine or $3 \mathrm{mg} / \mathrm{kg}$ morphine and $1 \mathrm{mg} / \mathrm{kg}$ naloxone) and one naloxone group $(1 \mathrm{mg} / \mathrm{kg})$. Naloxone was administrated $10 \mathrm{~min}$ before morphine or saline. Two control groups were included: One pretreated with $0.9 \%$ saline before doxorubicin infusion, a control for pretreatment, and one pretreated with $0.9 \%$ saline before KHBB infusion, a control for the experimental model. All pretreatment was administrated by i.p. injection. Each group included six rats. $60 \mathrm{~min}$ after pretreatment, hearts were excised and Langendorff perfused with the following protocol: 15-min stabilization period, after which physiological parameters were recorded for $5 \mathrm{~min}$ and effluate was collected. Hearts then received 45 min of infusion with undiluted $2 \mathrm{mg} / \mathrm{mL}$ doxorubicin at a rate of $0.05 \mathrm{~mL} / \mathrm{min}$ (or KHBB for the control group). Physiological data were collected immediately after the infusion was terminated. Ultimately, a 5-min wash-out period followed after which we collected effluates, and the Langendorff protocol was terminated. Treatment protocols and perfusion protocols are illustrated in Fig. 1.

\section{Quantification of Doxorubicin and Doxorubicinol}

Doxorubicin and doxorubicinol were quantified by highperformance liquid chromatography (HPLC-MS/MS) (1200 series RRLC, Agilent Technologies, USA) coupled with an Agilent 6410 triple quadrupole mass spectrometer using positive electrospray ionization (Agilent Technologies, USA). Frozen left ventricular tissue was minced and weighted out in a glass tube with a screw cap and homogenized in physiological saline $(2 \mathrm{~mL} / 100 \mathrm{mg}$ tissue $)$ with a tissue homogenizer (Ultra Turrax, Sigma Aldrich, Germany). $1000 \mu \mathrm{L}$ of sample was added to $100 \mu \mathrm{L}$ of daunorubicin as internal standard (IS) and $200 \mu \mathrm{L}$ of buffer (1M TRIZMA, $\mathrm{pH}$ 11.1) and mixed well before extraction with $4 \mathrm{~mL}$ ethyl acetate/heptane $(80 / 20 \mathrm{vol} / \mathrm{vol})$. The samples were mixed using a rotary blender for $15 \mathrm{~min}$ and then centrifuged at $3500 \mathrm{rpm}$ for $10 \mathrm{~min}$ at $10{ }^{\circ} \mathrm{C}$. The organic phase was evaporated to dryness at $50{ }^{\circ} \mathrm{C}$ under nitrogen then dissolved in $100 \mu \mathrm{L}$ of methanol followed by $100 \mu \mathrm{L}$ of distilled water. The extract was mixed thoroughly and transferred to silanized vials before analysis. $25 \mu \mathrm{L}$ of extract was injected and separated on a Zorbax SB-Aq $(2.1 \times 50 \mathrm{~mm}, 1.8 \mu \mathrm{m}$ particles, Agilent Technologies, USA) column using gradient elution with acetonitrile and $0.1 \%$ formic acid in water. Quantification were performed using multiple reaction monitoring mode at $\mathrm{m} /$ $z 546.1 \rightarrow 363.1$ for doxorubicinol, $\mathrm{m} / z$ z $544.1 \rightarrow 361.1$ for doxorubicin and $\mathrm{m} / \mathrm{z}, 528.1 \rightarrow 321.1$ for daunorubicin (IS).

Effluate Content of $\mathrm{H}_{2} \mathrm{O}_{2}$

$\mathrm{H}_{2} \mathrm{O}_{2}$ in cardiac effluate was measured using an Apollo 4000 electrochemical detection system (World Precision Instruments, Sarasota, FL, USA). The electrode was calibrated using nine serial dilutions of $\mathrm{H}_{2} \mathrm{O}_{2}$ in phosphatebuffered saline with added aniline. The current recorded from the effluate was then calculated as $\mu \mathrm{M} \mathrm{H}_{2} \mathrm{O}_{2}$. Samples were kept at $37{ }^{\circ} \mathrm{C}$ during measurement. The electrode was allowed 3 min of stabilization and $1 \mathrm{~min}$ of recording.

\section{Effluate Content of TnT}

TnT in cardiac effluate was measured using an Elecsys 2010 immunoassay analyzer (Roche Diagnostics Norway AS, Oslo, Norway), based on the sandwich principle. Total duration of assay: $9 \mathrm{~min}$. First incubation: $50 \mu \mathrm{L}$ of sample, a biotinylated monoclonal cardiac TnT-specific antibody, 
Fig. 1 Treatment and perfusion protocols

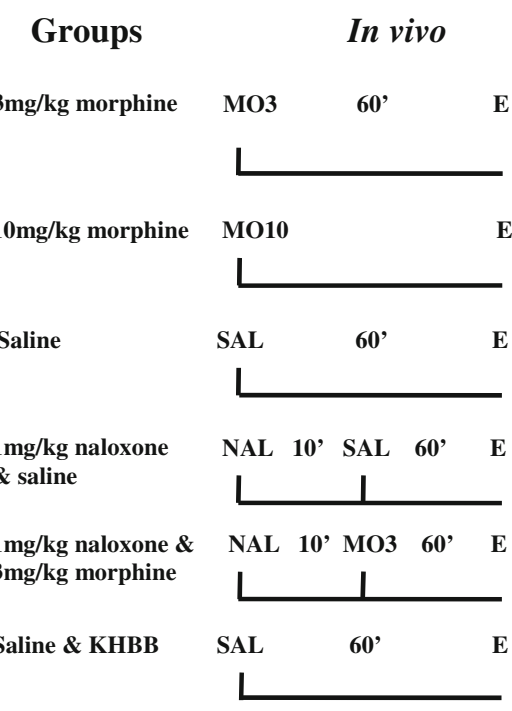

MO3 = 3mg/ $/ \mathrm{kg}$ morphine

MO10 $=10 \mathrm{mg} / \mathrm{kg}$ morphine

DOX = doxorubicin

NAL $=$ naloxone

SAL = saline । = intraperitoneal injection

$E=$ excision of heart and end of in vivo protocol

6 rats in each group
Ex vivo Langendorff perfusion

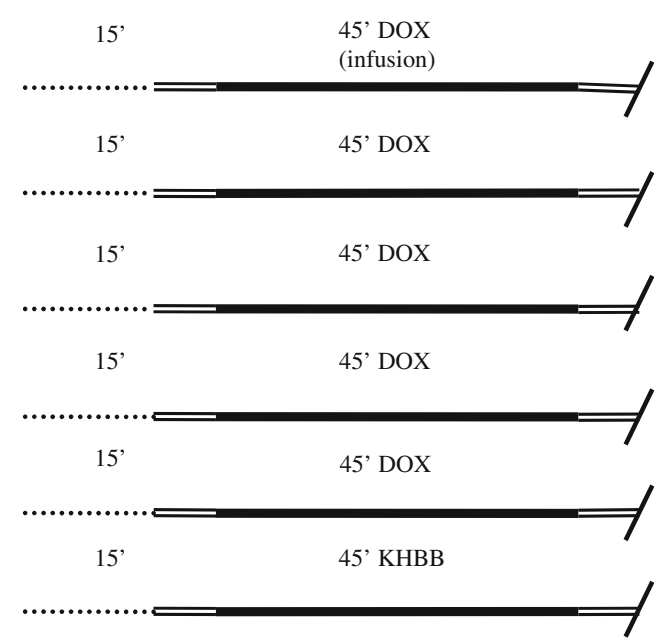

Stabilisation period

Recording

Infusion

6 hearts in each group and a monoclonal cardiac TnT-specific antibody labeled with a ruthenium complex (tris(2,2-bipyridyl)ruthenium(II)-complex(Ru(bpy))) reacted to form a sandwich complex. Second incubation: After addition of streptavidin-coated microparticles, the complex became bound to the solid phase via interaction of biotin and streptavidin. The reaction mixture was aspirated into the measuring cell where the microparticles were magnetically captured onto the surface of the electrode. Unbound substances were then removed with ProCell. Application of a voltage to the electrode then induced chemiluminescent emission which was measured by a photomultiplier. Results were determined via a calibration curve which was instrument specifically generated by 2-point calibration and a master curve (5-point calibration) provided via the reagent barcode. Detection limit was $5.0 \mathrm{ng} / \mathrm{L}$.

\section{Statistics}

All results are reported as mean values \pm standard deviation (SD) in tables. Data were collected at two time points: before doxorubicin infusion and at the end of infusion. Groups were compared with regards to parameters with a one-way analysis of variance and subsequently fisher's protected least-significant difference test. SPSS for windows version 17.0 was used, and $p<0.05$ was considered statistically significant.

\section{Results}

All physiological results are presented in Table 1 and pharmacological and biochemical results in Table 2. Results from comparison of the two morphine groups have been left out of Tables 1 and 2 as they showed no statistically significant difference between the two different morphine doses.

Reduction in cardiac function measured by LVDP and release of troponin and $\mathrm{H}_{2} \mathrm{O}_{2}$ were evident in hearts from morphine-treated rats before infusion with doxorubicin was started. Hearts from rats pretreated with $3 \mathrm{mg} / \mathrm{kg}$ $(84.3 \pm 8.3 \mathrm{mmHg})$ and $10 \mathrm{mg} / \mathrm{kg} \quad(76.8 \pm 5.8 \mathrm{mmHg})$ morphine demonstrated significantly $(p<0.05)$ lower values of LVDP at baseline, compared with hearts pretreated with saline $(149.8 \pm 10.7 \mathrm{mmHg})$. There was no difference in LVDP at baseline in hearts from rats pretreated with naloxone, or naloxone and $3 \mathrm{mg} / \mathrm{kg}$ morphine compared with hearts pretreated with saline.

The reduction in cardiac function measured by LVDP and release of troponin and $\mathrm{H}_{2} \mathrm{O}_{2}$ were more pronounced in 
Table 1 Physiological results

\begin{tabular}{|c|c|c|c|c|c|c|}
\hline & $\begin{array}{l}\text { Group } 1 \\
3 \mathrm{mg} / \mathrm{kg} \\
\text { morphine }\end{array}$ & $\begin{array}{l}\text { Group } 2 \\
10 \mathrm{mg} / \mathrm{kg} \\
\text { morphine }\end{array}$ & $\begin{array}{l}\text { Group } 3 \\
\text { Saline }\end{array}$ & $\begin{array}{l}\text { Group } 4 \\
1 \mathrm{mg} / \mathrm{kg} \text { naloxone } \\
\text { and saline }\end{array}$ & $\begin{array}{l}\text { Group } 5 \\
1 \mathrm{mg} / \mathrm{kg} \text { naloxone } \\
\text { and } 3 \mathrm{mg} / \mathrm{kg} \\
\text { morphine }\end{array}$ & $\begin{array}{l}\text { Group } 6 \\
\text { Saline control }\end{array}$ \\
\hline $\begin{array}{l}\text { LVDP } \\
\text { baseline } \\
\text { (mmHg) }\end{array}$ & $84.3 \pm 8.3 *$ & $76.8 \pm 5.8^{*}$ & $149.8 \pm 10.7$ & $145.3 \pm 7.7$ & $139.8 \pm 9.1$ & $145.7 \pm 9.6$ \\
\hline $\begin{array}{l}\text { LVDP end } \\
(\mathrm{mmHg})\end{array}$ & $52.8 \pm 11.1^{*}$ & $50.7 \pm 10.9^{*}$ & $102.5 \pm 5.9$ & $99.8 \pm 7.7$ & $100.3 \pm 11.1$ & $135.5 \pm 6.6^{*}$ \\
\hline $\operatorname{LVDP}(\%)$ & $62.9 \pm 13.3$ & $66.2 \pm 14.7$ & $68.8 \pm 7.5$ & $68.6 \pm 2.6$ & $71.9 \pm 7.9$ & $93.1 \pm 2.4 *$ \\
\hline $\begin{array}{l}\text { LVEDP } \\
\text { baseline } \\
(\mathrm{mmHg})\end{array}$ & $5.6 \pm 1.6$ & $6.1 \pm 1.3$ & $6.2 \pm 1.5$ & $5.6 \pm 1.4$ & $6.5 \pm 1.3$ & $7.4 \pm 1.0$ \\
\hline $\begin{array}{l}\text { LVEDP end } \\
(\mathrm{mmHg})\end{array}$ & $23.2 \pm 1.8^{*}$ & $22.4 \pm 1.8^{*}$ & $13.2 \pm 1.7$ & $13.5 \pm 1.8$ & $12.9 \pm 1.4$ & $8.6 \pm 0.6^{*}$ \\
\hline LVEDP (\%) & $440.7 \pm 124.9^{*}$ & $381.2 \pm 94.1^{*}$ & $219.2 \pm 44.2$ & $254.4 \pm 70.7$ & $206.1 \pm 53.9$ & $117.7 \pm 14.5$ \\
\hline $\begin{array}{l}\text { AoP baseline } \\
\quad(\mathrm{mmHg})\end{array}$ & $92.5 \pm 4.4^{*}$ & $89.5 \pm 6.1 *$ & $103.3 \pm 4.1$ & $107.0 \pm 3.1$ & $104.2 \pm 5.2$ & $107.7 \pm 2.7$ \\
\hline $\begin{array}{l}\text { AoP end } \\
\quad(\mathrm{mmHg})\end{array}$ & $150.3 \pm 5.8^{*}$ & $151.5 \pm 6.6^{*}$ & $164.0 \pm 5.8$ & $159.2 \pm 7.0$ & $160.0 \pm 7.2$ & $114.6 \pm 4.6^{*}$ \\
\hline AoP $(\%)$ & $162.9 \pm 11.9$ & $169.7 \pm 10.1$ & $158.8 \pm 6.5$ & $148.7 \pm 2.9$ & $154.1 \pm 12.6$ & $106.4 \pm 2.9 *$ \\
\hline $\begin{array}{l}\mathrm{d} p / \mathrm{d} t_{\max } \\
\text { baseline } \\
(\mathrm{mmHg})\end{array}$ & $2,855.3 \pm 378.5^{*}$ & $2,733.5 \pm 458.5^{*}$ & $4,677.7 \pm 306.2$ & $4,934.8 \pm 205.7$ & $4,710.2 \pm 125.5$ & $4,788.7 \pm 291.4$ \\
\hline $\begin{array}{l}\mathrm{d} p / \mathrm{d} t_{\max } \text { end } \\
(\mathrm{mmHg})\end{array}$ & $1,551.0 \pm 293.8^{*}$ & $1,542.3 \pm 278.9^{*}$ & $2,873.8 \pm 418.4$ & $2,902.8 \pm 423.8$ & $2,779.5 \pm 588.1$ & $4,378.3 \pm 449.5^{*}$ \\
\hline $\mathrm{d} p / \mathrm{d} t_{\max }(\%)$ & $54.7 \pm 10.2$ & $58.0 \pm 15.2$ & $61.8 \pm 10.6$ & $58.7 \pm 7.4$ & $58.9 \pm 12.2$ & $91.3 \pm 4.6^{*}$ \\
\hline $\begin{array}{l}\mathrm{d} p / \mathrm{d} t_{\min } \\
\text { baseline } \\
(\mathrm{mmHg})\end{array}$ & $-1,767.8 \pm 125.9^{*}$ & $-1,853.0 \pm 164.8^{*}$ & $-3,191.5 \pm 279.3$ & $-3,184.8 \pm 308.9$ & $-3,049.5 \pm 263.5$ & $-3,746.5 \pm 220.2^{*}$ \\
\hline $\begin{array}{l}\mathrm{d} p / \mathrm{d} t_{\min } \text { end } \\
(\mathrm{mmHg})\end{array}$ & $-1,170.7 \pm 107.9^{*}$ & $-1,326.2 \pm 143.2^{*}$ & $-2,148.5 \pm 378.8$ & $-2,186.8 \pm 196.6$ & $-1,970.5 \pm 177.9$ & $-3,587.8 \pm 282.0^{*}$ \\
\hline $\mathrm{d} p / \mathrm{d} t_{\min }(\%)$ & $66.3 \pm 5.4$ & $71.9 \pm 8.5$ & $67.1 \pm 8.5$ & $69.5 \pm 11.6$ & $65.1 \pm 9.0$ & $95.8 \pm 4.5^{*}$ \\
\hline
\end{tabular}

Values presented as mean \pm SD

* Significantly different from hearts in group $3, p<0.05$

hearts from morphine-treated rats after doxorubicin exposure, compared with hearts from saline or naloxone-treated rats. Hearts from rats pretreated with $3 \mathrm{mg} / \mathrm{kg}(52.8 \pm$ $11.1 \mathrm{mmHg})$ and $10 \mathrm{mg} / \mathrm{kg}(50.7 \pm 10.9 \mathrm{mmHg})$ morphine demonstrated significantly $(p<0.05)$ lower values of LVDP at the end of the doxorubicin infusion, compared with hearts pretreated with saline $(102.5 \pm 5.9 \mathrm{mmHg})$. There was no difference in LVDP at the end of the doxorubicin infusion in hearts from rats pretreated with naloxone, or naloxone and $3 \mathrm{mg} / \mathrm{kg}$ morphine, compared with hearts pretreated with saline. However, reduction in physiological parameters in per cent was similar in all groups $1-5$, irrespective of pretreatment during $45 \mathrm{~min}$ of doxorubicin infusion.

At the end of infusion, hearts from rats pretreated with $3 \mathrm{mg} /$ $\mathrm{kg}(23.2 \pm 1.8 \mathrm{mmHg})$ and $10 \mathrm{mg} / \mathrm{kg}(22.4 \pm 1.8 \mathrm{mmHg})$ morphine demonstrated significantly $(p<0.05)$ higher LVEDP, compared with hearts pretreated with saline $(13.2 \pm 1.7 \mathrm{mmHg})$. There was no significant difference in LVEDP in the naloxone-pretreated groups, compared with the saline-pretreated group, at the end of infusion.

Hearts from rats pretreated with $3 \mathrm{mg} / \mathrm{kg}(33.6 \pm 0.5$ $\mu \mathrm{M})$ and $10 \mathrm{mg} / \mathrm{kg}(39.5 \pm 5.8 \mu \mathrm{M})$ morphine demonstrated significantly $(p<0.05)$ increased release of $\mathrm{H}_{2} \mathrm{O}_{2}$ in effluate compared with hearts pretreated with saline $(28.4 \pm 2.1 \mu \mathrm{M})$, at baseline. Similarly, $\mathrm{H}_{2} \mathrm{O}_{2}$ in effluate from rats pretreated with $3 \mathrm{mg} / \mathrm{kg}(40.9 \pm 3.6 \mu \mathrm{M})$ and $10 \mathrm{mg} / \mathrm{kg}(45.6 \pm 1.3 \mu \mathrm{M})$ morphine was increased at the end of infusion, compared with $\mathrm{H}_{2} \mathrm{O}_{2}$ in effluate from rats pretreated with saline $(34.9 \pm 1.2 \mu \mathrm{M})$.

Hearts from rats pretreated with $3 \mathrm{mg} / \mathrm{kg} \quad(63.3 \pm$ $20.7 \mathrm{ng} / \mathrm{L})$ and $10 \mathrm{mg} / \mathrm{kg}(84.8 \pm 20.3 \mathrm{ng} / \mathrm{L})$ morphine 
Table 2 Pharmacological and biochemical results

\begin{tabular}{|c|c|c|c|c|c|c|}
\hline & $\begin{array}{l}\text { Group } 1 \\
3 \mathrm{mg} / \mathrm{kg} \\
\text { morphine }\end{array}$ & $\begin{array}{l}\text { Group } 2 \\
10 \mathrm{mg} / \mathrm{kg} \\
\text { morphine }\end{array}$ & $\begin{array}{l}\text { Group } 3 \\
\text { Saline }\end{array}$ & $\begin{array}{l}\text { Group } 4 \\
1 \mathrm{mg} / \mathrm{kg} \\
\text { naloxone and } \\
\text { Saline }\end{array}$ & $\begin{array}{l}\text { Group } 5 \\
1 \mathrm{mg} / \mathrm{kg} \\
\text { naloxone and } \\
3 \mathrm{mg} / \mathrm{kg} \\
\text { morphine }\end{array}$ & $\begin{array}{l}\text { Group } 6 \\
\text { Saline } \\
\text { control }\end{array}$ \\
\hline $\begin{array}{l}\text { Doxorubicin myocardial tissue } \\
\text { concentration at the end of } \\
\text { experiments (nmol/g) }\end{array}$ & $205.6 \pm 27.6^{*}$ & $213.7 \pm 11.1^{*}$ & $168.5 \pm 9.5$ & $185.2 \pm 7.7$ & $188.8 \pm 11.7$ & 0.0 \\
\hline $\begin{array}{l}\text { Doxorubicinol myocardial tissue } \\
\text { concentration at the end of } \\
\text { experiments }(\mathrm{nmol} / \mathrm{g})\end{array}$ & $3.1 \pm 0.2$ & $4.0 \pm 1.4$ & $3.2 \pm 0.5$ & $1.4 \pm 0.5^{*}$ & $2.1 \pm 0.5^{*}$ & 0.0 \\
\hline $\begin{array}{l}\text { Troponin } \mathrm{T} \text { in effluate before } \\
\text { doxorubicin exposure (ng/L) }\end{array}$ & $63.3 \pm 20.7 *$ & $84.8 \pm 20.3^{*}$ & $22.7 \pm 7.4$ & $39.0 \pm 15.7$ & $47.0 \pm 4.6$ & $16.8 \pm 3.8$ \\
\hline $\begin{array}{l}\text { Troponin } \mathrm{T} \text { in effluate after doxorubicin } \\
\text { exposure (ng/L) }\end{array}$ & $321.5 \pm 108.5^{*}$ & $473.5 \pm 117.6^{*}$ & $129.2 \pm 6.6$ & $177.8 \pm 4.6$ & $187.2 \pm 8.2$ & $36.0 \pm 10.0$ \\
\hline $\begin{array}{l}\mathrm{H}_{2} \mathrm{O}_{2} \text { in effluate before doxorubicin } \\
\text { exposure }(\mu \mathrm{M})\end{array}$ & $33.6 \pm 0.5^{*}$ & $39.5 \pm 5.8^{*}$ & $28.4 \pm 2.1$ & $26.9 \pm 3.6$ & $26.9 \pm 3.6$ & $27.6 \pm 3.3$ \\
\hline $\begin{array}{l}\mathrm{H}_{2} \mathrm{O}_{2} \text { in effluate after doxorubicin } \\
\text { exposure }(\mu \mathrm{M})\end{array}$ & $40.9 \pm 3.6^{*}$ & $45.6 \pm 1.3^{*}$ & $34.9 \pm 1.2$ & $33.3 \pm 1.8$ & $33.9 \pm 2.5$ & $28.8 \pm 3.4^{*}$ \\
\hline
\end{tabular}

Values presented as mean $\pm \mathrm{SD}$

* Significantly different from hearts in group $3, p<0.0 .5$

demonstrated significantly $(p<0.05)$ higher values of TnT at baseline, compared with hearts pretreated with saline $(22.7 \pm 7.4 \mathrm{ng} / \mathrm{L})$. There was no difference in $\mathrm{TnT}$ at baseline in hearts from rats pretreated with naloxone, or naloxone and $3 \mathrm{mg} / \mathrm{kg}$ morphine compared with hearts pretreated with saline. Similarly, hearts from rats pretreated with $3 \mathrm{mg} / \mathrm{kg} \quad(321.5 \pm 108.5 \mathrm{ng} / \mathrm{L})$ and $10 \mathrm{mg} / \mathrm{kg}$ $(473.5 \pm 117.6 \mathrm{ng} / \mathrm{L})$ morphine demonstrated significantly $(p<0.05)$ higher values of TnT at the end of the doxorubicin infusion, compared with hearts pretreated with saline $(129.2 \pm 6.6 \mathrm{ng} / \mathrm{L})$. There was no difference in $\mathrm{TnT}$ at the end of the doxorubicin infusion in hearts from rats pretreated with naloxone, or naloxone and $3 \mathrm{mg} / \mathrm{kg}$ morphine compared with hearts pretreated with saline.

Myocardial content of doxorubicin was significantly $(p<0.05)$ higher in the $3 \mathrm{mg} / \mathrm{kg}(205.6 \pm 27.6 \mathrm{nmol} / \mathrm{g})$ and $10 \mathrm{mg} / \mathrm{kg}(213.7 \pm 11.1 \mathrm{nmol} / \mathrm{g})$ morphine group compared with the saline-pretreated group (168.5 \pm $9.5 \mathrm{nmol} / \mathrm{g}$ ), at the end of infusion. The concentration of doxorubicin in the perfusate was measured to a mean of $5.42 \pm 1.98 \mu \mathrm{M}$ based on samples $(n=30)$ from the aortic cannula of the Langendorff system without hearts mounted. Hearts were paced to 300 beats per minute; thus, data on heart rate have been left out of Table 1 .

\section{Discussion and Conclusion}

The main observation in the present results is that the increased mortality associated with morphine could be related to enhanced cardiotoxicity. In the pilot study [28], we established an in vivo model with three groups: eight rats were pretreated with an i.p. injection of $3 \mathrm{mg} / \mathrm{kg}$ morphine, and 8 rats were pretreated with an i.p. injection of $0.9 \%$ saline, $60 \mathrm{~min}$ prior to a $3 \mathrm{mg} / \mathrm{kg}$ doxorubicin i.p. injection every other day for 11 days, up to a cumulative dose of $12 \mathrm{mg} / \mathrm{kg}$ doxorubicin. Five rats were pretreated with an i.p. injection of $0.9 \%$ saline 60 min prior to an i.p. injection of $0.9 \%$ saline every other day for 11 days. On day 12 , hearts from the three groups were planned to be excised and Langendorff perfused for comparison of physiological and biochemical indices of cardiotoxicity. However, 6 out of 8 rats in the group pretreated with morphine died before day 12 and did not complete the treatment protocol. Mortality was evident in the group by day $9(n=1)$ and by days 10 and $11(n=5)$. The remaining two rats were moribund and euthanasia was performed. Thus, physiological parameters from rats pretreated with morphine were not available for comparison with the other groups, and myocardial tissue was discarded due to risk of postmortem redistribution of drugs. Based on these results, we hypothesized that the interaction between doxorubicin and morphine could result in increased cardiotoxicity. The results from the pilot study were unexpected because a similar study [11] found morphine to be protective against doxorubicin-induced cardiotoxicity in rat. This study pretreated rats with an i.p. dose of $10 \mathrm{mg} / \mathrm{kg}$ morphine $30 \mathrm{~min}$ prior to doxorubicin. Doxorubicin $(1.25 \mathrm{mg} / \mathrm{kg}$ i.p.) was administrated four times per week for 4 weeks, with a total cumulative dose of $20 \mathrm{mg} / \mathrm{kg}$. 
Cardioprotective efficacy of morphine was performed by analyzing the electrocardiographic parameters (QRS complexes and ST segments) and contractility force of left ventricular papillary muscle, and these parameters were improved in rats pretreated with morphine. Morphine also reduced mortality in this study. We measured LVDP and derived indices. The morphine dose is the same in our study. However, we delivered it $60 \mathrm{~min}$ prior to doxorubicin. In early preconditioning, a memory phase of up to $2 \mathrm{~h}$ after trigging has been reported in which protection is demonstrated [12, 13]. Theoretically, this should allow for opioid receptor activation in the memory phase of preconditioning in the rat myocardium.

Enhanced mortality by a combination of morphine and doxorubicin has previously been demonstrated in mice where morphine pretreatment caused a dose-dependent increase in plasma doxorubicin [14]. In our study, rats were pretreated in vivo with morphine before the hearts were isolated and exposed to doxorubicin ex vivo. Pretreatment with morphine in vivo, irrespective of dose, is associated with a cardiodepressive effect in isolated hearts combined with increased release of $\mathrm{H}_{2} \mathrm{O}_{2}$ and TnT. After exposure to doxorubicin ex vivo, isolated hearts from rats pretreated with morphine, irrespective of dose, demonstrate increased release of $\mathrm{H}_{2} \mathrm{O}_{2}$ and $\mathrm{TnT}$, increased myocardial contracture and increased myocardial accumulation of doxorubicin. These effects were abolished when naloxone was administrated before morphine in pretreatment. The enhanced cardiotoxicity of pretreatment with morphine was in particular evident by LVEDP. Myocardial contracture assessed by an increase in LVEDP suggests that pretreatment with morphine enhanced diastolic dysfunction during doxorubicin infusion. Diastolic dysfunction is proposed to reflect impaired calcium handling which together with generation of oxygen species are proposed as toxic mechanisms of anthracyclines [3]. Interestingly, diastolic dysfunction is proposed to precede systolic dysfunction in chronic anthracycline cardiotoxicity and suggested as an early marker of subsequent heart failure in the clinic [3].

By using i.p. administration of $4 \mathrm{mg} / \mathrm{kg}$ morphine, a study on rats found peak plasma concentrations of about 1 $\mu \mathrm{M}$ after $8 \mathrm{~min}$ with a half-life of about $46 \mathrm{~min}$ [15]. Theoretically, this should allow for opioid receptor activation in the memory phase of preconditioning in the rat myocardium. In early preconditioning, a memory phase of up to $2 \mathrm{~h}$ after trigging has been reported in which protection is demonstrated $[12,13]$. We used a dose of $3 \mathrm{mg} /$ $\mathrm{kg}$ i.p and added a dosage of morphine of $10 \mathrm{mg} / \mathrm{kg}$ as reported by others $[11,16,17]$, to investigate whether the dose used in the pilot study was too low to illicit a protective effect. However, both 3 and $10 \mathrm{mg} / \mathrm{kg}$ morphine i.p. had a cardiodepressive effect prior to exposure to doxorubicin. In this present study, cardiodepression with a theoretical morphine peak plasma concentration of approximately $1 \mu \mathrm{M}$ is in accordance with previous observations [18].

In vitro studies have shown that opioids directly decrease the contractile response of isolated ventricular cardiomyocytes to electrical stimulation [19]. One hypothesis explaining morphine-induced decreased contractility is that morphine induced the increase in generation of free radicals that we measured at baseline. A study of pretreatment of chick embryonic ventricular myocytes with $1 \mu \mathrm{M}$ morphine before $1 \mathrm{~h}$ of ischemia and $3 \mathrm{~h}$ of reoxygenation found a two-fold increased free radical production before ischemia compared with controls [20]. The increase in free radical signals with morphine was abolished by 5-hydroxydecanoate, a selective mitochondrial $\mathrm{K}_{\mathrm{ATP}}$-channel antagonist [10]. We observed that the cardiodepressive effect was associated with increased release of $\mathrm{H}_{2} \mathrm{O}_{2}$ in morphine-treated hearts. However, after doxorubicin infusion, this was associated with further increased release of hydrogen peroxide and increased myocardial contracture evident by increased LVEDP. This raises the question whether an increase in generation of free radicals induced by morphine not only induced a cardiodepressive effect prior to doxorubicin, but produced additive myocardial damage to that produced by doxorubicin. $\mathrm{H}_{2} \mathrm{O}_{2}$ is an important by-product of oxidative metabolism and is a major contributor in oxidative stressinduced functional and metabolic dysfunction [21, 22]. An experiment that exposed isolated perfused rat hearts to $200 \mu \mathrm{M} \mathrm{H} \mathrm{H}_{2} \mathrm{O}_{2}$ for $30 \mathrm{~min}$ resulted in a time-dependent depression of myocardial contractility and a $1000 \%$ elevation in LVEDP [4]. Similar results have been reported in isolated rat hearts [23, 24]. We found a depression in LVDP of approximately $40 \%$ in the morphine groups and $30 \%$ in the saline-pretreated group after 45 min of doxorubicin exposure. This effect was associated with approximately $400 \%$ elevation in LVEDP in the morphine groups, irrespective of dose, compared with $200 \%$ in the saline group with levels of $\mathrm{H}_{2} \mathrm{O}_{2}$ in the range of $35-45 \mu \mathrm{M}$. Thus, our results suggest that additive free radical damage generated by morphine and doxorubicin could result in contractile dysfunction. $\mathrm{H}_{2} \mathrm{O}_{2}$ mediates increased endothelial permeability and may increase the extravasation of doxorubicin and alter its distribution in the myocardium $[25,26]$. Thus, a potential change in endothelial permeability due to increased $\mathrm{H}_{2} \mathrm{O}_{2}$ can explain the increased content of doxorubicin in hearts from rats pretreated with morphine in our study.

The concentration of doxorubicin in the perfusate was measured to $5.42 \pm 1.98 \mu \mathrm{M}$. A non-physiological concentration could mask a protective effect of morphine. However, $\mathrm{C}_{\max }$ of plasma doxorubicin following a $30 \mathrm{mg} /$ $\mathrm{m}^{2}$ i.v. bolus dose in humans is reported to be $3 \mu \mathrm{mol} / \mathrm{L}$, 
with cellular levels 30-100-fold higher than that of the plasma [27]. We do not know in which compartment of the myocardium the accumulation of doxorubicin took place. The main coronary vascular bed is unlikely due to our wash-out procedure. Furthermore, the reduced contractile function is not due to vasoconstrictive effects since we used a model with volume-regulated perfusion. However, doxorubicin could accumulate in the extracellular space as well as in the cardiomyocytes. The reduced contractile function suggests that at least a part of the accumulation affects the cardiomyocytes. We observed that $\mathrm{H}_{2} \mathrm{O}_{2}$ levels are altered by morphine in combination with doxorubicin. However, there is insufficient assessment of why this might lead to enhanced damage, and of the possibility that other reactive species may also be involved in the effects seen. Further studies are needed to assess this.

The Langendorff model bypasses the pharmacokinetic phase associated with drug metabolism and only measures the direct action of the drug in the myocardium. The interaction of morphine and doxorubicin in vivo could involve systemic effects that secondarily influenced the function of the heart. In the present study, we wanted to investigate how doxorubicin affects a heart that has already been exposed to morphine in vivo based on our findings in the pilot study where morphine was administrated in a similar way. Ideally, heart functional parameters could be measured in vivo after morphine and subsequent doxorubicin administration, but direct cardiotoxic effects could be difficult to separate from indirect systemic effects. Furthermore, both morphine and doxorubicin could be administrated in sequence in Langendorff hearts to study their effects exclusively in the heart, but pharmacokinetic effects would lack as mentioned above.

In conclusion, we found that pretreatment with morphine is associated with a cardiodepressive effect in isolated rat hearts combined with increased release of $\mathrm{H}_{2} \mathrm{O}_{2}$ and TnT. After exposure to doxorubicin ex vivo, isolated hearts from rats pretreated with morphine are associated with increased release of $\mathrm{H}_{2} \mathrm{O}_{2}$ and TnT, increased myocardial contracture and accumulation of doxorubicin. Morphine increases intracellular free radical signals, and this is an important component of the signaling pathways by which morphine mimics preconditioning in cardiomyocytes. However, results in our pilot study and the present study suggest that these pathways, although promising interventions to reduce cardiotoxicity of anthracyclines, are also associated with risk of additional damage in the rats.

Acknowledgments This work was supported by Bergen Heart Foundation.

Conflict of interest None declared.
Open Access This article is distributed under the terms of the Creative Commons Attribution License which permits any use, distribution, and reproduction in any medium, provided the original author(s) and the source are credited.

\section{References}

1. Minotti, G., et al. (2004). Anthracyclines: Molecular advances and pharmacologic developments in antitumor activity and cardiotoxicity. Pharmacological Reviews, 56(2), 185-229.

2. Robert, J. (2007). Preclinical assessment of anthracycline cardiotoxicity in laboratory animals: Predictiveness and pitfalls. Cell Biology and Toxicology, 23(1), 27-37.

3. Ferreira, A. L., Matsubara, L. S., \& Matsubara, B. B. (2008). Anthracycline-induced cardiotoxicity. Cardiovascular and Hematological Agents in Medicinal Chemistry, 6(4), 278-281.

4. Gan, X. T., et al. (1998). Protective effects against hydrogen peroxide-induced toxicity by activators of the ATP-sensitive potassium channel in isolated rat hearts. Journal of Molecular and Cellular Cardiology, 30(1), 33-41.

5. Li, W., et al. (2009). Procyanidins produce significant attenuation of doxorubicin-induced cardiotoxicity via suppression of oxidative stress. Basic and Clinical Pharmacology and Toxicology, 104(3), 192-197.

6. Cardinale, D., \& Sandri, M. T. (2010). Role of biomarkers in chemotherapy-induced cardiotoxicity. Progress in Cardiovascular Diseases, 53(2), 121-129.

7. Cardinale, D., et al. (2000). Left ventricular dysfunction predicted by early troponin I release after high-dose chemotherapy. Journal of the American College of Cardiology, 36(2), 517-522.

8. Sandri, M. T., et al. (2003). Minor increases in plasma troponin I predict decreased left ventricular ejection fraction after high-dose chemotherapy. Clinical Chemistry, 49(2), 248-252.

9. Reagan, W. J., et al. (2013). Comparison of cardiac troponin I and $\mathrm{T}$, including the evaluation of an ultrasensitive assay, as indicators of doxorubicin-induced cardiotoxicity. Toxicologic Pathology, 41(8), 1146-1158.

10. McPherson, B. C., \& Yao, Z. (2001). Morphine mimics preconditioning via free radical signals and mitochondrial K(ATP) channels in myocytes. Circulation, 103(2), 290-295.

11. Kelishomi, R. B., et al. (2008). Morphine is protective against doxorubicin-induced cardiotoxicity in rat. Toxicology, 243(1-2), 96-104.

12. Gross, G. J. (2003). Role of opioids in acute and delayed preconditioning. Journal of Molecular and Cellular Cardiology, 35(7), 709-718.

13. Schultz, J. E., \& Gross, G. J. (2001). Opioids and cardioprotection. Pharmacology and Therapeutics, 89(2), 123-137.

14. Innis, J. D., Meyer, M., \& Hurwitz, A. (1987). A novel acute toxicity resulting from the administration of morphine and adriamycin to mice. Toxicology and Applied Pharmacology, 90(3), $445-453$.

15. Zheng, M., McErlane, K. M., \& Ong, M. C. (1998). High-performance liquid chromatography-mass spectrometry-mass spectrometry analysis of morphine and morphine metabolites and its application to a pharmacokinetic study in male Sprague-Dawley rats. Journal of Pharmaceutical and Biomedical Analysis, 16(6), 971-980.

16. Kiumehr, S., et al. (2005). Preconditioning of the rat randompattern skin flap: Modulation by opioids. British Journal of Plastic Surgery, 58(1), 58-64.

17. Frassdorf, J., et al. (2005). Morphine induces late cardioprotection in rat hearts in vivo: The involvement of opioid receptors and 
nuclear transcription factor kappaB. Anesthesia and Analgesia, 101(4), 934-941. Table of contents.

18. Suzer, O., et al. (1998). Direct cardiac effects in isolated perfused rat hearts measured at increasing concentrations of morphine, alfentanil, fentanyl, ketamine, etomidate, thiopentone, midazolam and propofol. European Journal of Anaesthesiology, 15(4), 480-485.

19. Wenzlaff, H., Stein, B., \& Teschemacher, H. (1998). Diminution of contractile response by kappa-opioid receptor agonists in isolated rat ventricular cardiomyocytes is mediated via a pertussis toxin-sensitive G protein. Naunyn-Schmiedeberg's Archives of Pharmacology, 358(3), 360-366.

20. McPherson, B. C., \& Yao, Z. (2001). Signal transduction of opioid-induced cardioprotection in ischemia-reperfusion. Anesthesiology, 94(6), 1082-1088.

21. Konz, K. H., et al. (1989). Diastolic dysfunction of perfused rat hearts induced by hydrogen peroxide. Protective effect of selenium. Journal of Molecular and Cellular Cardiology, 21(8), 789-795.

22. Sahin, A. S., Gormus, N., \& Duman, A. (2007). Preconditioning with levosimendan prevents contractile dysfunction due to $\mathrm{H} 2 \mathrm{O} 2-$ induced oxidative stress in human myocardium. Journal of Cardiovascular Pharmacology, 50(4), 419-423.
23. Akahira, M., et al. (1998). Protective effect of prazosin on the hydrogen peroxide-induced derangements in the isolated perfused rat heart. Life Sciences, 62(19), 1755-1766.

24. Matsumura, H., et al. (1998). Protective effects of ranolazine, a novel anti-ischemic drug, on the hydrogen peroxide-induced derangements in isolated, perfused rat heart: Comparison with dichloroacetate. The Japanese Journal of Pharmacology, 77(1), 31-39.

25. Kevil, C. G., et al. (2000). H(2)O(2)-mediated permeability: Role of MAPK and occludin. American Journal of Physiology Cell Physiology, 279(1), C21-C30.

26. Kevil, C. G., Oshima, T., \& Alexander, J. S. (2001). The role of p38 MAP kinase in hydrogen peroxide mediated endothelial solute permeability. Endothelium, 8(2), 107-116.

27. Speth, P. A., et al. (1987). Cellular and plasma adriamycin concentrations in long-term infusion therapy of leukemia patients. Cancer Chemotherapy and Pharmacology, 20(4), 305-310.

28. Aune, M. A rat model to assess interventions to reduce cardiotoxicity of anthracyclines: Does pre-treatment with morphine reduce the cardiotoxicity of doxorubicin? Master thesis in Pharmacy 2008, University of Bergen. 